Nuntius Antiquus, Belo Horizonte, v. 12, n. 1, p. 159-176, 2016

\title{
Por amor a Hs.
}

\section{For the love of $\mathrm{Hs}$.}

Ana Vicentini de Azevedo

Psicanalista

Association Psychanalytique Encore (Paris)

Universidade de Brasília

Brasília, DF - Brasil

anavica2009@gmail.com

Resumo: O presente trabalho discute alguns aspectos e conceitualizações de Eros, tal como elaborados em três registros discursivos: na obra poética e vida da escritora americana Hilda Doolittle (HD); em alguns pontos da teoria freudiana. $\mathrm{O}$ terceiro registro discute algumas maneiras pelas quais essa noção se entretece na relação entre Freud e Hilda, primeiramente como sua analisanda e, mais tarde, como amiga. Alguns aspectos e efeitos fundamentais da prática psicanalítica são salientados nessa discussão. Uma atenção especial é dada ao poema-livro Helen in Egypt, de HD, onde Eros aparece em sua dupla-face de amor e morte. Essa dimensão dupla é tratada como um conceito nas elaborações freudianas sobre a pulsão de vida e a pulsão de morte.

Palavras-chave: Eros; HD; Freud; Helen; feminino; pulsões; prática psicanalítica.

Abstract: The paper discusses some aspects and conceptualisations of Eros, as elaborated in three different registers: the poetic work and life of the American poet Hilda Doolittle (HD); in some moments of Freud's psychoanalytic theory. The third register brings to the fore some of the ways in which this mythic notion is intertwined in Freud and Hilda's relationship, first as analyst/analysand, and later as friends. Key 
dimensions and effects of psychoanalytic clinical practice are highlighted in this discussion. Especial attention is also given to HD's book-poem Helen in Egypt, in which Eros is portrayed in its double-face dimension of love and death. This dimension is given a conceptual status in Freud's elaboration in terms of the libidinal and the death drives.

Keywords: Eros; HD; Freud; Helen; femininity; the drives; psychoanalytic practice.

Artigo recebido em 6 de agosto de 2015 Aprovado para publicação em 8 de outubro de 2015

The lunatic, the lover and the poet

Are of imagination all compact.

$[\ldots]$

The lover, all as frantic,

Sees Helen's beauty in a brow of Egypt.

And as imagination bodies forth

The forms of things unknown, the poet's pen,

Turns them to shapes and gives to airy nothing

A local habitation and a name.

W. Shakespeare, A Midsummer Night's Dream

Em março de 1933, aos setenta e sete anos, e não sem hesitação, Freud decidiu aceitar em análise a jovem poeta americana, Hilda Doolittle. Um gesto que chama a atenção, pois ele já não aceitava mais novos pacientes, em face de seu estado de saúde.

As possíveis razões que conduziram Freud a acolher essa paciente nos convidam a inquisições especulativas. Digno de nota, primeiramente, é o fato de Hilda Doolittle ter vindo recomendada de diversos segmentos do mundo intelectual de então, desde Havellock Ellis, passando por Oliver Sachs, até a historiadora e ensaísta Bryher (Winifred Ellerman), que era filha do homem mais rico da Inglaterra e mecenas de artistas, psicanalistas e de associações e congressos psicanalíticos. Ela se tornou, em 1919, companheira de Hilda Doolittle, ou HD - a como é conhecida -, até o final de sua vida, em 1961. É Bryher quem nos dá uma pista para a aceitação de Freud: "Sigmund Freud is sold on artists" (Sigmund Freud 
é completamente fascinado por artistas) (FRIEDMAN, 2002, p. 10). ${ }^{1}$ De fato, como ele próprio sempre sustentou - e nos alertou -, no que concerne às explorações da vida psíquica, o artista precede o analista.

Outro possível motivo para a aceitação da nova paciente apareceu nas leituras das cartas, poemas e narrativas autobiográficas de HD. Encontrei o registro de um grande incômodo de Freud, quando a poeta chega para sua primeira sessão em Bergasse 19, Viena, ${ }^{2}$ em março de 1933: HD foi a primeira e única paciente que sequer olhou para Freud! Seus olhos e seu interesse se voltaram inteiramente para a rica coleção de antiguidades do analista. "You are the only person who has ever come into this room and looked at the things in the room before looking at me" (HD, 1974, p. 98), reclama Freud para HD.

Esse primeiro encontro foi emblemático da relação que se estabelece entre o analista e a poeta, para além dos protocolos do tratamento. Freud e HD (e posteriormente Bryher) construíram uma duradoura relação, sobretudo epistolar, ${ }^{3}$ que causaria estranhamento a certas ortodoxias psicanalíticas, inclusive em nossos dias. Nas palavras de HD, analista e analisanda tiveram "uma relação em verso livre!".

A devoção de ambos pelo mundo grego constituiu, a meu ver, o sedimento dessa relação lírico-amorosa-analítica. Para a poeta, a Grécia era a terra prometida para onde Bryher iria levá-la tão logo ela se recuperasse de um dos vários colapsos e crises psíquicas que permeavam sua vida. Para HD, a Grécia era a terra de sua predileção espiritual e a "geografia de seus sonhos" (HD, 1974, p. 40-41).

Do ponto de vista de Freud, sabemos que o edifício teórico da psicanálisese tem assento no mito e na literatura gregas, muito além do que se pode supor a partir do decantado "complexo de Édipo". Em meio à multiplicidade de citações, definições e alusões ao pensamento grego, que Freud faz ao longo de sua extensa obra, destaco o seguinte comentário, ou melhor, uma retificação conceitual: "what psychoanalys called sexuality [...] had more resemblance to the all-inclusive and all-preserving Eros of

\footnotetext{
${ }^{1}$ Carta de HD a Havelock Ellis, de 27 de dezembro de 1932.

${ }^{2}$ Endereço da residência e consultório de Freud.

${ }^{3}$ Freud escreveu 24 cartas para HD e 19 para Bryher. Infelizmente, as cartas delas para Freud "não sobreviveram à destruição de muitos de seus documentos na fuga de Viena para Londres", nos informa Susan S. Friedman (2002, p. xi).
} 
162 Nuntius Antiquus, Belo Horizonte, v. 12, n. 1, p. 159-176, 2016

Plato's Symposium" (FREUD, 1925[1924], 1961, p. 218). ${ }^{4}$ Eros auxilia Freud a conceitualizar a sexualidade humana como um domínio distinto da genitalidade e é, sobretudo, o significante por excelência para a construção de um dos pilares conceituais da psicanálise - as pulsões (o outro sendo o inconsciente). Para os propósitos deste trabalho, sublinho que a dualidade pulsional que estrutura a psicanálise tem, em Eros, uma de suas vertentes; em Thánatos a outra. Fora do vocabulário grego, essas pulsões são chamadas de pulsão de vida e pulsão de morte, respectivamente. Essa dimensão será também central na relação de Hilda Doolittlecom Freud, como veremos no que esse segue.

O vínculo devocional de Freud com a Hélade também aparece em uma perspectiva mais íntima de sua vida. Em sua dramática fuga de Viena, em 1938, ele escolheu um único objeto a ser levado em seu derradeiro exílio. Tratava-se de uma pequena estatueta de bronze de Pallas Athena. A justificativa: para que eles pudessem ficar "sob a proteção de Athena", conforme ele escreve em agradecimento a Marie Bonaparte (FRIEDMAN, 2002, p. 32). De fato, em se tratando de Freud, estamos diante de uma enciclopédia das artes e das musas, como indicou Lacan.

\section{Aproximações de HD a Freud}

Parte da tradição crítica de HD salienta que o motivo que a levou a Freud teria sido a tentativa de resolução de sua bissexualidade. Devo dizer que jamais encontrei qualquer referência de $\mathrm{HD}$ a esse suposto "problema". Por outro lado, o histórico de crises psíquicas de Hilda é sem dúvida um fator determinante em sua busca por análise. E, como na maior parte dos casos, há sempre algo, um episódio pontual e determinante que leva alguém a passar da "vontade de fazer análise" para uma mise en acte efetiva dessa demanda.

Hilda procura análise com Freud, pois padece de um sintoma insuportável para um escritor: writer's block, como ela chamava.

\footnotetext{
${ }^{4}$ Todas as referências a obras de Freud seguem o padrão internacionalmente adotado: entre parênteses, após o nome do autor, vem o ano de sua primeira publicação; entre colchetes, o ano de sua escrita, quando for o caso. A seguir, vem o ano de publicação da edição utilizada. Nas referências bibliográficas, o ano de publicação da edição utilizada vem após o título da obra citada.
} 
It was not exactly true that I was going to see Freud to become a psycho-analyst. I was empty. I wanted to free myself of repetitive thoughts and experiences. I did not realize just what it was that wanted, but I knew that I was drifting. (QUINET, 2015, p. 25)

De fato, esse empuxo para o mar avassalador do delírio pede um dique, um ponto de basta.

É importante notar que, mesmo em um de seus delírios alucinatórios mais significativos, em 1919, HD conseguiu escrever um caderno que ela intitula de Notes on Thought and Vision, posteriormente transformado em livro e publicado em 1982. Portanto, há algo novo nesse momento que a paralisa para a escrita e a impulsiona para Freud.

Alguns elementos biográficos ajudam na aproximação de Hilda e Freud. Ela deixou os Estados Unidos pela Inglaterra, em 1911, quando tinha apenas 25 anos. Lá ela se torna "more royal than the Royals", como se diz nesse seu país de adoção, do qual ela adota inclusive a inflexão aristocrática de enunciação. Essa profunda identificação idealizante não a afasta, entretanto, de seus vínculos familiares profundos. Na Primeira Grande Guerra, Hilda perde seu amado irmão, Gilbert, e seu pai, que morre em consequência de um ataque cardíaco ao saber da morte do filho. A Primeira Guerra lhe tira dois grandes amores. O terceiro, também “espiritual", por DH Lawrence, é perdido por causa de sua tumultuada vida erótica ao final da guerra. Nessa época, ela, apesar de ser esposa do poeta Richard Aldington, engravida do músico Cecil Gray e tem um aborto em função das ameaças e do abandono de seu amante. Amor e guerra entrelaçam-se traumaticamente na vida de Hilda. Como bem mais tarde ela irá conseguir formular,

Even the gods' plans

are shaped by another -

Eros? Eris?

(HD, Helen in Egypt, Parte II, Leuké, Livro I, Poema 5. Kindle Edition $)^{5}$

\footnotetext{
${ }^{5} \mathrm{O}$ poema, de aproximadamente 208 páginas, é dividido em três partes: Pallinode (com 7 livros); Leuké (com 7 livros) e Eidolon (6 livros). Cada livro é composto, em média, por 8 poemas, em tercetos.
} 
Essa tensão entre as forças conflitivas de Eros e Éris, ou melhor, ente amor e morte irá permear a obra de $\mathrm{HD}$, na esteira do que vimos acima sobre a teoria freudiana. Vejamos.

Os anos de 1932-1933 trazem uma Europa já convulsionada pela ascensão do Nazismo, e paira no ar, especialmente para almas mais sensíveis como Hilda, a assustadora sombra de outra grande devastação. Eros e Eris novamente preparam sua conjugação. Não é à toa que uma atividade erótica como a criação artística e, em particular, a poesia de Hilda, paralisem-se.

\begin{abstract}
"I have tried to decipher my tragedy in verse, in prose, and in autobiographical novels. But I'm completely blocked [...] It seems that the only way for me to overcome the disaster is to tell HIM the story", admit Hilda. (QUINET, 2015, p. 30)
\end{abstract}

Com Freud, e em Freud, a escrita como decifração daquilo que Hilda chama epicamente de sua "lenda" (HD, 1974, p. v) adquire matizes produtivos e múltiplos sentidos (nos vários sentidos do termo). O esboço acima que HD faz de sua situação analítica nos mostra o lugar que Freud ocupa para ela - um lugar de escuta e acolhimento de sua história, um porto seguro, no qual as ondas dos delírios podem parar de se revolver.

Ouvimos Hilda em uma sessão: "I don't want to talk today. I am drifting out to sea. But I know I am safe, can return at any moment to terra firma" (HD, 1974, p. 133). Essa terra firme recebe outros nomes ao longo da sua vida: "o velho Édipo", "o Professor", "Papa”. Não apenas para ela, mas por meio de suas palavras, Freud surge como alguém que "deu à luz um novo mundo". De fato, tratou-se de uma profícua "relação em verso livre", a partir da qual muitas coisas se criaram.

\title{
2 A primeira Helena
}

A questão do feminino é um ponto nodal da análise de Hilda com Freud. Como ela mesma insiste, "as mulheres são perfeitas". No começo de uma determinada sessão, no entanto, essa perfeição, ou melhor, sua concepção do feminino, é matizada. Ao entrar no consultório de Freud, tal como na primeira vez, em vez de olhar para o analista, ela é capturada por uma estatueta em sua escrivaninha. 
HD: This statue - what is it?

Freud, desviando a atenção para outra: This is my favourite. Pallas Athena. She's perfect, except she's lost her spear.

HD: Pallas Athena, spearless. She's perfect with her loss.

(QUINET, 2015, p. 41-42)

A perda ou a falta não são privilégio das mulheres, mas inerentes a todo ser falante, sabemos em psicanálise, especialmente depois de Jacques Lacan. Mas a beleza na imperfeição de uma deusa grega, tão idealizada e poderosa, tanto para Freud quanto para HD, é uma, dentre muitas, formas de reedição do laço amoroso entre eles. Mais uma vez, é no horizonte do mundo grego que analista e analisanda trabalham. A questão do feminino, que a estatueta de Pallas Athena põe em relevo para ambos, reitera um agudo problema com o qual Freud sempre se confrontou e que HD busca em sua análise.

Freud teria confessado a Marie Bonaparte que, após mais de 30 anos de pesquisas, ele não havia conseguido saber "o que quer uma mulher?" Insisto no artigo indefinido singular da pergunta de Freud, e não em sua versão mais conhecida, pluralizante - "o que querem as mulheres" -, por razões que veremos abaixo. Já antecipo que, mesmo que Freud tenha entregado os pontos em relação aos mistérios do desejo feminino, e que Lacan os tenha computado e desenvolvido, essa pergunta sobre a questão da mulher deve ser ouvida nos termos exatos da formulação freudiana e sob a égide da máxima do mestre de que o artista precede o analista.

A confissão de Hilda Doolittle sobre sua paralisia literária sutilmente articula a questão da mulher com a dimensão do desejo, inclusive situando tal articulação como mola propulsora de suaanálise com Freud: "eu não sabia o que era aquilo que eu queria" (QUINET, 2015, p. 25). Avançando com certa rapidez, podemos ver, tanto em Freud quanto em HD, o invólucro enigmático que envolve a questão da mulher e do desejo.

\section{Uma primeira Helena}

Em se tratando dessa enigmática articulação, é a Grécia que mais uma vez nos oferece uma poderosa metáfora para olharmos a questão mais de perto. Refiro-me, obviamente, à figura de Helena e à Helena como figura, no âmbito do enigma do desejo feminino. Helena foi voluntariamente com Páris ou foi raptada? Ela amava Menelau? 
Quem Helena amou? Em suma, “qual o desejo de Helena?” é talvez uma interrogação que subjaz na literatura clássica, desde Homero, passando por Ésquilo até Platão (para não mencionar os latinos, nem os modernos).

Sob esse paradigma da mulher - inacessivelmente misteriosa e, talvez por isso, tão bela - uma miríade de Helenas é tecida, e nela encontramos, em latência, o inquietante enigma do que quer uma mulher. Por outro lado, essas múltiplas Helenas podem ser vistas à luz do que Goethe observou no sentido de que as mulheres são o último vaso no qual podemos despejar nossas idealidades (ECKERMAN, s.d., p. 168). ${ }^{6}$

No vocabulário psicanalítico, damos o nome a esse "vaso"de "objeto a", causa do desejo, ou seja, um objeto construído nos moldes do desejo do homem. Ao comentar o estatuo de "objeto a" da mulher em relação ao desejo do homem, Lacan parece parafrasear Goethe: "é verdadeiramente uma confirmação de que, quando se é homem, vê-se na parceira aquilo em que nos baseamos nós mesmos, aquilo em que a gente se baseia narcisicamente" (LACAN, (1972-1973), 1985, p. 116-117). ${ }^{7}$

Vamos deixar em latência essa visada psicanalítica da mulher enquanto "objeto a", de que "Helena" é emblemática, e voltarmos o foco para sua figuração literária. Com a ressalva de que, nosso objeto de atenção aqui não é essa pluralidade de Helenas de que nos falam as tradições literária e filosófica, mas, sim, uma Helena trazida à luz por HD. O primeiro traço dessa figuração do feminino, que HD põe em relevo, aparece em seu poema, "Helen", de 1928:
All Greece hates
the still eyes in the white face, the lustre as of olives
where she stands,
and the white hands.
All Greece reviles
the wan face when she smiles,

\footnotetext{
${ }^{6}$ As palavras exatas de Goethe, segundo Eckerman, são: “As mulheres [...] essa é a única possibilidade que nos resta, a nós, modernos, para nela resumirmos toda a nossa idealidade". A conversa continua em torno de Byron, cuja Helena é, para Goethe, "um monumento imortal do amor". (ECKERMAN, s.d., p. 169).

${ }^{7}$ As referências aos seminários de Lacan seguem o padrão internacionalmente adotado: após o nome do autor, vem o ano em que foi ministrado o seminário. Ao final da citação, indica-se o ano de publicação da edição utilizada.
} 


\author{
hating it deeper still \\ when it grows wan and white, \\ remembering past enchantments \\ and past ills.
}

Greece sees unmoved, God's daughter, born of love, the beauty of cool feet and slenderest knees, could love indeed the maid, only if she were laid, white ash amid funeral cypresses. (HD, 1983, p. 154-155)

"All Greece hates" é uma sentença fantasmagórica e ameaçadora que abre o poema, construindo, de um lado, a totalidade do mundo grego, all Greece. De outro, aparece Helena, em seus traços singulares: "the still eyes in the white face": "the white hands", the wan face when she smiles". Ou seja, ao "todo" que é a Grécia, se destaca o "um", singular. Um enquadramento interessante para situar a questão da mulher e do desejo. Como a pluralidade de figurações de Helena na tradição nos leva a propor, o caminho a ser seguido nessa interrogação é o caráter singular e - indefinido - de uma mulher, e não a busca d'A mulher.

Dito de outro modo, a uma lógica do "todo", a uma ambição universalizante do discurso de "toda Grécia", temos uma singularidade que fere a totalidade, um não-todo, no neologismo de Lacan, a partir da lógica aristotélica. ${ }^{8}$ A preocupação de Lacan é com possíveis relações entre a lógica formal e os sexos, sem incorrer no problema no qual tropeçou Freud em relação ao feminino: a diferença sexual não pode ser pensada nos parâmetros de presença e ausência do falo. Todos os seres falantes estão inscritos nessa ordem fálica, mas há aqueles que são nãotodo fálicos, ao invés de não fálico. ${ }^{9}$ Aliás, como os cômicos gregos nos mostraram, falo é aquele objeto que, nos kómoi, passa de mão em mão, é desejado por todos, e pertence a ninguém.

No poema "Helen", de HD, essa concepção do feminino como não-todo é fulgurante. De fato, o poeta precede o analista. Helena é

\footnotetext{
${ }^{8}$ Ver sobre esse desenvolvimento de Lacan acerca da lógica Aristotélica, o trabalho referencial de Le Gauffey (2009).

${ }^{9}$ Além do trabalho de Le Gauffey, deve-se notar a importante discussão sobre a questão feita por Barbara Cassin em Jacques le sophiste (2012).
} 
grega, mas é também não-toda grega, na medida que é não-toda ódio. Esse arcabouço é fundamental para pensarmos a posição da mulher, que aparece em uma cena analítica entre Freud e HD. Afigura emblemática nessa ocasião é Pallas Athena, porém destituída de sua "lança". A lógica do ter ou não ter (a lança) vigora no registro do "todo": ou se é todo (fálico), ou se é "menos", posto que lhe falta algo para ser completo, todo. Ausência e presença de qualquer atributo são critérios insuficientes e inadequados para se pensar a sexualidade humana, em particular a diferença entre os sexos e a singularidade de cada um deles.

O poema de 1928, de HD, esboça, avant-la-lettre, esse arcabouço lógico-psicanalítico. De imediato, ela já figura como não-toda grega, por não partilhar do ódio de "all Greece". Aliás, ela é "God's daughter, born of love". Outros traços de Helena fogem a seus atributos universais mais marcados e marcantes, notadamente sua hiperbólica beleza: ela tampouco é "toda-bela". Aqui Helena figura em seu fugaz "branco", caracterizado como evanescente nas aliterações "the white face", "where she stands, / and the white hands", "the wan face when she smiles", "when it grows wan and white".

Essa é uma Helena fugidia, incapturável, tal como o eídolon, que aparece com clareza em Eurípides. Nesse poema, HD compõe imagens, traços simbólicos de Helena. Imagens e símbolos são os termos iniciais que Lacan utiliza para circunscrever a posição mulher. Mais tarde, esses significantes serão condensados na categoria "semblant", esse faz de conta do qual o ator grego e sua máscara têm tudo a nos ensinar: é um mistério "que joga com o imaginário para [...] cativar esse desconhecido que é o desejo" (SOLER, 2006, p. 33). Essa mascarada feminina, que é protagonista nas danças e contra-danças entre os sexos, indica que, mesmo estando sujeita ao imperativo do todo (e subjetivamente inscrita nessa lógica), a mulher pode ter acesso a uma posição suplementar, onde vigora outra lógica, diversa da dicotomia de ter ou não ter (o pênis), como se trabalhou e ainda se trabalha em algumas tradições pós-freudianas.

\section{Helena, encore}

De volta à HD, devemos observar que, em 1928, ela já é uma cuidadosa leitora de psicanálise, e é desta, sugiro, que ela retira o leitmotif de seu mais importante trabalho sobre Helena - "Helen in Egypt", escrito entre 1952-1954 e publicado pouco antes de sua morte, em 1963. A 
perspectivaque se anuncia no poema de 28 traz à baila a tensão entre hate, revile, e love. All Greece hates, all Greece reviles, aquela que é filha do amor. Porém, essa Grécia que odeia pode vir a amar, desde que a morte se faça igualmente presente: "[it]could Love indeed the maid/ only if she were laid/white ash amid funeral cypresses".

No livro-poema, Helen in Egypt, essa tensão entre amor e ódio, entre Eros e Éris, esboçada anteriormente, aparece aqui com a força estruturante que esse par tem em Freud. Para este, essas forças propulsoras, as pulsões, marcam-se por um fusionamento, ou seja, Eros e pulsão de morte entrelaçam-se na constituição de todo psiquismo. Aliás, observa Freud, Eros "encarna a vontade de viver". Mas arremata, e isso é o mais importante: "há uma pulsão que visa à restauração de um estado anterior de coisas". Ou seja, a essa tendência poderosa que nos impele à vida e à criação, há outra, silenciosa, conservadora, que se opõe à vitalidade de Eros, e com a qual dialeticamente se mescla (FREUD, (1920) 1955, p. 36ss.). Em Freud, Eros e Thánatos se fusionam.

Essa íntima conjugação entre amor e morte torna-se o tópos propulsor de Helen in Egypt, bem como na análise de HD (para não dizer na constituição do humano como tal, na visada psicanalítica).

Quase 30 anos após seu primeiro poema sobre Helena, e após seus dois momentos de análise com Freud, em 1933 e depois em 1934, HD amplia sua primeira Helena, entretecida em traços mais firmes e densos. Tributária da versão de Eurípedes (cujo Íon ela traduziu, com os cumprimentos de Freud), ${ }^{10}$ essa Helena é novamente o tópos a produzir mais de mil velas, folhas, páginas. Escrito entre os anos de 1952-1954, a "nova" Helena de HD é uma transcriação que retoma e expande a tensão presente no poema de 28. Por razões de escopo, apenas alguns aspectos desse longo e intricado poema-livro serão tratados aqui.

O principal deles retoma e amplia a tensão entre Eros e Eris, presente no poema de 28 , e algo avassalador na vida de Hilda Doolittle. Já no Livro II da primeira parte, Palinódia, Hilda/Helen interroga: "does Zeus decree that, forever/Love should be Born of war?" O Eros of flaming wing [...]/ let my heart be filled with peace" (HD. Helen in Egypt, Parte II, Leuké, Livro II, Poema 8. Kindle Edition). Mais adiante, o enigma é reiterado com novos significantes: "será o amor o disfarce da Morte,

\footnotetext{
${ }^{10}$ A publicação aparece em 1937. Cf. Friedman (2002, p. xi).
} 
ou o véu da Morte?" (HD. Helen in Egypt, Parte II, Leuké, Livro III, Poema 7. Kindle Edition).

Na segunda parte do poema, na idílica ilha de Leuké, cenário da recriação do amor entre Achilles e Helena, Eros é flexionado. Na tentativa de afastá-la de Aquiles, Páris indica que "esse tipo de amor [...] destrói não somente o objeto amoroso, mas também a si próprio" (HD. Helen in Egypt, Parte II, Leuké, Livro III, Poema 5. Kindle Edition). Tal força destrutiva de Eros, também tributária da mitologia grega, encontra um paralelo no campo da psicanálise: o que Freud chamou de fusionamento pulsional, e que atravessa a vida erótica de Hilda.

Mas é na última parte de Helen in Egypt onde encontramos uma fecunda articulação feita por HD entre Eros e Thánatos. Aliás, tal como a pulsão de morte, a tensão entre essas forças percorre sub-repticiamente todo o poema. Porém, é na última parte, significativamente chamada de Eídolon, que os lados da mesma moeda de troca entre todos os humanos têm lugar de destaque. Como exímia artífice da palavra, Hilda traz a língua francesa para fazer confluir, em ato de linguagem, a pulsão de vida e pulsãode morte. L'Amour, La Mort, repetem-se e confundem-se nos últimos livros da parte final do poema-livro.

A nomeação e assunção desse par antitético e inextricável, Eros e Thánatos-L'Amour/La Mort, ao final do poema, nos convida a um movimento de leitura retroativa. São eles o leitmotif da obra e, sem receio de recair em "interpretoses", são a mola propulsora da vida de Hilda e de sua busca por análise. Essa com-fusão, que antes era fonte de crises, fantasias perturbadoras e até de alucinações, parece encontrar um lugar em seu quebra-cabeça mental.

Hilda atribui a Freud a preocupação central com Eros e Morte: "those two were the chief subjects - in fact the only subjects - of the Professor's eternal preoccupation.”(HD, 1974, p. 103). Como podemos ver por essa breve leitura de Helen in Egypt e de seu tributo a Freud, a própria Hilda está imersa nessas águas misteriosas.

Depois de assumir L'Amour, La Mort como "a experiência última [the ultimate experience]" (HD. Helen in Egypt, Parte III, Eidolon, Livro VI, Poema 1. Kindle Edition), Hilda pode retomar sua tessitura poética a partir de outro lugar. Em outras palavras, não somente o processo analítico, mas a sua elaboração, conjugada à recriação dos gregos, sua marca poética, permitem que ela ocupe outro lugar, metaforizado também por meio de outra referência grega - Penélope. Por intermédio dessa 
figura, Hilda formula suas recriações em Tribute to Freud e Helen in Egypt nos seguintes termos:

the million personal things

things remembered, forgotten,

remembered again, assembled and re-assembled in different order as thoughts and emotions [...].

(HD. Helen in Egypt, Parte III, Eidolon, Livro VI, Poema 1. Kindle Edition)

Um processo tão profundo como este só pode conduzir a novas trilhas, a veredas: "the simple path/refutes at last/ the threat of the Labyrinth/the Sphinx is seen [...] " (HD. Helen in Egypt, Parte III, Eidolon, Livro VI, Poema 8. Kindle Edition). Um caminho nada simples, mas que ao final the permite vislumbrar a Esfinge como algo no limite do conhecível e, finalmente, poder viver, sob a sombra de Penélope: "my mind goes on, spinning the infinite thread" (HD. Helen in Egypt, Parte III, Eidolon, Livro VI, Poema 5. Kindle Edition).

\section{Um H. a mais: Hilda, seguidora de Hermes}

HD é uma poeta que inaugura, ou pode-se dizer, nomeia o movimento poético conhecido como Imagista. ${ }^{11}$ A noção de imagem poética que orienta esse grupo pode ser sintetizada nas palavras do próprio Pound como "algo que apresenta um complexo emocional e intelectual em um instante de tempo" (PREMINGER; BROGAN, 1993, p. 514). Ou seja, Pound aproxima a imagem poética do ideograma, entendido como uma imagem que traz de imediato a concretude da experiência. No vocabulário poético de HD, especialmente em Helen in Egypt, essa noção de imagem ideogramática tem o nome de hieróglifo. Este, para $\mathrm{HD}$, funciona como uma metáfora da própria escrita, como também de si mesma qual letra cifrada:

Helen achieves the difficult task of translating a symbol in time, into timeless-time or hieroglyph or ancient Egyptian time [...]. She says she is instructed, she is enchanted rather. For from the

\footnotetext{
${ }^{11}$ É o que nos conta HD em seu End to Torment: a memoir of Ezra Pound (1979, p. 18). Também farão parte do movimento os poetas Amy Lowell, Richard Aldington, F.S. Flint, William Carlos William, entre outros.
} 
172 Nuntius Antiquus, Belo Horizonte, v. 12, n. 1, p. 159-176, 2016

depth of her racial inheritance, she invokes (as the perceptive visitor to Egypt must always do) the symbol or the 'letter' [...]

(HD. Helen in Egypt, Parte I, Pallinode, Livro I, Poema 7. Kindle Edition)

A letra como condensação de Helena é um paralelo evidente (uma identificação, diríamos em psicanálise) entre HD, como letra, e Helena como uma protoimagem da poeta americana e da escrita poética: "[Helen] herself is the writing", nos conta Hilda na narrativa que precede o terceiro poema do Livro II, da Palinódia.

Temos aí, de maneira condensada, a concepção de HD da escrita como tradução, como deslocamento; em suma, como uma produção de metáforas, na trilha da língua grega. Letra, hieróglifo e símbolo são significantes da escrita poética, em uma concepção consoante com o epítome dos Imagistas: a exposição, e não a narrativa, de um complexo de intelecto e emoção, em um instante de tempo, parafraseando Pound.

É a busca, paralisada, dessas imagens, desses símbolos que impele Hilda a Freud. Desse encontro, ela produz uma reflexão poética em dois tempos, agrupada sob o título de Tribute to Freud.

Essa obra de HD constitui fonte preciosa de informação sobre a prática clínica de Freud, sendo, até hoje, objeto de apreço por parte da comunidade psicanalítica, mas surpreendentemente pouco conhecida. Sua primeira publicação no Brasil é de 2012, e sua primeira edição em língua inglesa data de 1956. É essa edição que Ernest Jones, o mais respeitado biógrafo de Freud, avaliou nos seguintes termos: "the book [...] is surely the most delightful and precious appreciation of Freud's personality that is ever likely to be written (...) It will live as the most enchanting ornament of all the Freudian biographical literature" (HD, 1974, p. vi).

De minha parte, considero-o o depoimento mais rico de uma análise de que se tem conhecimento na literatura psicanalítica. Esse "ornamento encantador", esculpido por uma exímia artífice da palavra, brota da relação que se estabeleceu entre ela e Freud, presidida por Eros. Tribute to Freud, ou Por amor a Freud, é uma contundente declaração de amor e gratidão a alguém que, nas palavras de Hilda, "set me free to prophesy" (in QUINET, 2015, p. 24). Uma liberdade para "criar", que lhe possibilitou transformar o apelido - HD - que seu jovem amante, E. Pound, havia lhe dado em algo seu - um nome próprio para sustentar sua produção literária. 
“To 'Do-little!'was not for me. Ezra Pound had given me this penname when we're young lovers in America. But with old Oedipus I made it my royal signature, my symptom, my symbol, my letters" (in QUINET, 2015 , p. 23). Os que já trilharam esse "doce-amargo (glykýpikron)"12 percurso analítico sabem como é portentoso o que Hilda conseguiu fazer com HD. E é raro encontrarmos um testemunho tão conciso e contundente de uma análise bem-sucedida, como esse que nos dá Hilda.

Seu afã por interpretações, sentidos e decifrações dominam essa obra: o que são as letras, os símbolos, os hieróglifos? Ela própria é uma letra, um símbolo que pede decifração, ou seja, escrita e leitura (ou interpretação, como preferem alguns). "Upon the elaborate built-up of past memories [...] there fell a shadow, a writing-on-the-wall [...] [an] unfinished $S[. .$.$] the shadow of a question - is this it? [...] The Professor's$ explanations were too illuminating [...]; my bat-like thought-wings would beat painfully in that sudden search-light" (HD, 1974, p. 20-30).

Hilda está constantemente em busca deluzes interpretativas, de Hermes, outro H. a entretecer-se com os já atuam aqui. $\mathrm{O}$ afã interpretativo de Hilda é de tal ordem que, mesmo antes de começar sua análise com Freud, este lhe envia a seguinte carta-recomendação, de 20 de fevereiro de 1933: "I would like to ask you to refrain from dream analysis and anything else analytical for the time being] (FRIEDMAN, 2002, p. 19).

A insistente busca por explicações acerca de si, de suas imagens, sonhos e delírios nos leva a ver Hilda como um enigma, um "hieróglifo vivo" a pedir decifração: "God made the Picture/and matched it/ with a living hieroglyph", indica Hilda, por meio de seu duplo autoral, Helena (HD, Helen in Egypt, Parte I, Pallinode, Livro II, Poema 3. Kindle Edition). Esse hieróglifo tem uma origem precisa - o Egito, para onde Hilda leva Helena, sob a inspiração de Stesichorus e Eurípides. Seu Egito é traduzido, sempre sob a lupa de Helena, nos seguintes termos: "[Helena's] vision is wholly Greek, thought she return to the sacred Egypt for her final inspiration" (HD. Helen in Egypt, Parte I, Pallinode, Livro II, Poema 4. Kindle Edition).

Hilda recria Helena e recria-se por meio de Helena em um Egito onde pode brotar a "inspiração", nome místico que Hilda dá à criação artística, ou à mania divina, como chamaram outros a um processo tão

${ }^{12}$ A expressão é de Safo (frag. 19), para qualificar Eros: glykýpikron, traduzido por Joaquim Brasil Fontes como "doce-amargo" (FONTES, 1991, p. 331). 
174 Nuntius Antiquus, Belo Horizonte, v. 12, n. 1, p. 159-176, 2016

complexo e misterioso como esse. Esse Egito, tão libertário para a criação, é concebido, já em 1919, no delirante Notes on Thought and Vision, nos seguintes termos: "Egypt in terms of world-consciousness is the act of love. Hellas is a childborn" (HD, 1982, p. 37). No Egito governado por Eros, Hilda vai contrapor Helena, odiada por toda a Hélade, a uma Hélade/ Helena filha do amor. Na decantada homofonia entre Helena e Héllas, Hilda interpõe-se, formando um belo triângulo amoroso, bem ao gosto da vida erótica de nossa poeta. É também esse "Egito", ou esse âmbito, onde Eros pode reinar (no duplo sentido), que terá efeitos reparadores para Helena/Hilda.

\section{Cenas finais de um casamento}

HD chega para uma sessão e relata a Freud que na casa de DH Lawrence havia uma pintura de Osíris e, ao lado, uma estatueta de bronze de Ísis. Freud imediatamente lhe diz: "venha, vamos ver se conseguimos encontrá-los" (HD, 1974, p. 172). Nesse enlace amoroso, os dois se engajam em um processo exploratório, no qual Freud põe o foco, a search light, para Hilda empreender sua arqueologia.

O desfecho desse poema-analítico pode ser recontado de várias formas. Em nosso trabalho na casa de Freud, ${ }^{13}$ temos Hilda intensamente voltada para a decifração de "Writing on the Wall", um delírio que ela teve em Corfu. Em meio a sua fúria interpretativa, quando ela atribui freneticamente significados a seus hieróglifos, Freud intervém de maneira cortante:

Hilda: $[\ldots]$ There were three clear images on the wall [...] For me it was a creative experience... to work through the loss of my brother. The soldier was Gilbert, my brother who died in the front... The others...

Freud: What's your mother's name?

Hilda: Helen. Of course! Hellas is Greece!

Freud: Your mother was a painter. (QUINET, 2015, p. 39-40)

${ }^{13}$ Em novembro de 2013 e em julho de 2015, encenamos o texto Hilda \& Freud: Collected Words, no Freud Museum, em Londres, sob a direção de A. Quinet, onde interpretei o papel de Hilda Doolittle. 
Na última sessão relatada em Tribute to Freud, Freud coloca a estatueta de Pallas Athena nas mãos de Hilda. E ela acrescenta: "há uma outra Athené, ou Niké alada" (HD, 1974, p. 187). E a leitora e escriba de hieróglifos arremata:

Hilda: Pallas Athena, Winged Victory. Victory in German is Sieg; Mund in German is mouth. Sigmund - the voice of victory. Victory is our hieroglyph on the couch. Athena, Athens. Athens is a city set on a hill. Hill in German is Berg, and a path to reach it is Gasse. Bergasse! (QUINET, 2015, p. 42)

Em um rico processo que chamamos de associação livre, Hilda empreende cortes e faz novas costuras, às quais finalmente se juntam tantos amores: a Grécia, sua vida e Freud em sua vida. O fio de Eros, que aproximou e conduziu Hilda e Freud em uma épica jornada, leva-a agora a deixar Bergasse 19 para tomar sua própria estrada, como se faz ao final de uma análise.

A escrita e a leitura de símbolos, de imagens, de eidola continuarão a orientar Hilda até o final da vida. Porém, algo novo comparece nessa produção: "as the Professor said, there is always something more to find out" (HD, 1974, p. viii). Dessa inquietação, partilhamos todos nós, abençoados filhos de Eros.

Para Maria Cecília Miranda N. Coelho

\section{Referências}

CASSIN. B. Jacques, le sophiste: Lacan, logos et psychanalyse. Paris: Epel, 2012.

ECKERMANN. Conversações com Goethe. Lisboa: Vega, [s.d.].

FONTES, J.B. Eros, telecelão de mitos: a poesia de Safo de Lesbos. Sāo Paulo: Estação Liberdade, 1991.

FREUD. S. (1920). Beyond the pleasure principle. In: . The

Standard Edition of the Complete Psychological Works of Sigmund Freud (S.E.). Londres: The Hogarth Press, 1955. v. XVIII.

FREUD, S. (1925 [1924]). The Resistances to Psychoanalysis. In: . The Standard Edition of the Complete Psychological Works of $\overline{\text { Sigmun }}$ Freud (S.E.). Londres: The Hogarth Press, 1961. v. XIX. 
176 Nuntius Antiquus, Belo Horizonte, v. 12, n. 1, p. 159-176, 2016

FRIEDMAN, S.S. Analyzing Freud: Letters of HD, Bryher, and their circle. New York: New Directions Book, 2002.

HD. Tribute to Freud. New York: New Directions Book, 1974.

HD. End to torment: a memoir of Ezra Pound. New York: New Directions Book, 1979.

HD. Notes on thought and vision \& The wise Sappho. New York: New Directions Book, 1982.

HD. Helen in Egypt. New York: New Directions Book. Edição Kindle.

HD. Collected Poems 1912-1944. New York: New Directions Book, 1983.

LACAN, J. (1972-1973). O Seminário, livro XX. Mais, ainda. Rio de Janeiro: Jorge Zahar, 1985.

Le GAUFFEY, G. El notodo de Lacan: consistencia lógica, consecuencias clínicas. Buenos Aires: Ediciones Literales, 2007.

PREMINGER, A.; BROGAN, T.V.F. (Org.). The New Princeton Encyclopaedia of Poetry and Poetics. New Jersey: Princeton University Press, 1993.

QUINET, A. Hilda \& Freud: Collected Words. Londres: Karnack Books, 2015.

SOLER, C. O que Lacan dizia das mulheres. Rio de Janeiro: Jorge Zahar, 2006. 